\title{
Meta-analysis of postruminal microbial nitrogen flows in dairy cattle. II. Approaches to and implications of more mechanistic prediction
}

\author{
Robin R. White, ${ }^{*}$ Yairanex Roman-Garcia, $\dagger$ and Jeffrey L. Firkins $\dagger^{1}$ \\ *Department of Dairy Science, Virginia Tech, Blacksburg 24060 \\ †Department of Animal Sciences, The Ohio State University, Columbus 43210
}

\begin{abstract}
Several attempts have been made to quantify microbial protein flow from the rumen; however, few studies have evaluated tradeoffs between empirical equations (microbial $\mathrm{N}$ as a function of diet composition) and more mechanistic equations (microbial $\mathrm{N}$ as a function of ruminal carbohydrate digestibility). Although more mechanistic approaches have been touted because they represent more of the biology and thus might behave more appropriately in extreme scenarios, their precision is difficult to evaluate. The objective of this study was to derive equations describing starch, neutral detergent fiber (NDF), and organic matter total-tract and ruminal digestibilities; use these equations as inputs to equations predicting microbial $\mathrm{N}(\mathrm{MicN})$ production; and evaluate the implications of the different calculation methods in terms of their precision and accuracy. Models were evaluated based on root estimated variance $\left(\hat{\sigma}_{e}\right)$ and concordance correlation coefficients (CCC). Ruminal digestibility of NDF was positively associated with DMI and concentrations of NDF and $\mathrm{CP}$ and was negatively associated with concentration of starch and the ratio of acid detergent fiber to NDF $(\mathrm{CCC}=0.946)$. Apparent ruminal starch digestibility was increased by omasal sampling (compared with duodenal sampling), was positively associated with forage NDF and starch concentrations, and was negatively associated with wet forage DMI and total dietary DMI $(\mathrm{CCC}=0.908)$. Models were further evaluated by calculating fit statistics from a common data set, using stochastic simulation, and extreme scenario testing. In the stochastic simulation, variance in input variables were drawn from a multi-variate random normal distribution reflective of input measurement errors and predicting MicN while accounting for the measurement errors. Extreme scenario testing evaluated each MicN model against a data subset. When compared against
\end{abstract}

Received November 18, 2015

Accepted May 4, 2016.

${ }^{1}$ Corresponding author: firkins.1@osu.edu an identical data set, predicting MicN empirically had the lowest prediction error, though differences were slight $\left(\hat{\sigma}_{e} 23.3 \%\right.$ vs. 23.7 or $24.3 \%$ ), and highest concordance (0.52 vs. 0.48 or 0.44$)$ of any approach. Minimal differences were observed between empirical MicN prediction $\left(\hat{\sigma}_{e} 25.3 \%\right.$; CCC 0.530) and MicN prediction $\left(\hat{\sigma}_{e}\right.$ $25.3 \%$; CCC 0.532 ) from rumen carbohydrate digestibility in the stochastic analysis or extreme scenario testing. Despite the hypothesized benefits of a more mechanistic prediction approach, few differences between the calculation approaches were identified.

Key words: rumen microbial protein, meta-analysis, NDF digestibility, starch digestibility, intake

\section{INTRODUCTION}

Precision protein feeding is gaining interest in the dairy industry because dietary protein sources can be expensive and excessive $\mathrm{N}$ excretion is an environmental concern (Ndegwa et al., 2008; Lee et al., 2012; Reed et al., 2015). Precision protein feeding on dairy operations will be impractical until AA or MP requirements can be predicted with accuracy and precision. Systematic biases in model calculation structure such as errors in estimating microbial $\mathrm{N}$ are prohibitive to efforts to improve the profitability and sustainability of dairies and must be remediated.

Several attempts have been made at quantifying microbial $\mathrm{N}$ production (MicN) in dairy diets (Fox et al., 2004; Huhtanen and Hristov, 2009; Broderick et al., 2010). A series of evaluations of microbial protein predictions have also been undertaken (Bateman et al., 2001; Yu et al., 2003; Tedeschi et al., 2015). Although these exercises have been useful, few have evaluated the role of rumen carbohydrate digestibility on MicN flow based on actual carbohydrate digestibility (ruminal or total-tract), whereas other evaluations assumed that book or predicted digestibility values for feeds are accurate and unbiased (Huhtanen et al., 2009). Previous evaluations of microbial $\mathrm{N}$ predictions have had limited evaluation of ruminal digestibility predictions, and thus a more thorough evaluation of the role of unbiased 
estimates of ruminal carbohydrate digestibility on the prediction of postruminal MicN flows is warranted.

To more mechanistically represent the role of ruminal carbohydrate digestibility in microbial protein synthesis, it is useful to compare equation methods that directly predict MicN flow with those that predict ruminal carbohydrate (starch $+\mathrm{NDF}$ ) digestibility as a first step to subsequently multiply by a predicted efficiency of microbial protein synthesis (EMPS; MicN/ amount of carbohydrate degraded in the rumen). In a companion paper (Roman-Garcia et al., 2016), 3 equations estimating microbial protein were developed. These equations estimated MicN flow as a function of (1) diet composition, (2) ruminal digestibility of starch and NDF, or (3) ruminal digestibility of $\mathrm{OM}$ and EMPS. The compounding calculation structure of the latter 2 calculation methods might affect the precision and accuracy of the resultant MicN estimate, although the complexity might also help bound the equation responses in extreme input scenarios. A more thorough comparison of the compounding error structures of more mechanistic prediction approaches is necessary to better understand the effects of including ruminal carbohydrate digestibility equations in predictions of MicN.

The objectives of this study were to derive equations describing starch, NDF, and OM total-tract and ruminal digestibility; to use ruminal equations as inputs to predictions of ruminal MicN production; and to evaluate the implications of the different calculation methods in terms of their precision and accuracy. We hypothesized that more mechanistic approaches to estimating MicN would yield poorer statistical fit when compared with more empirical approaches but that the precision of mechanistically estimated MicN, given the potential global variation in input parameters, will be favorable compared with the empirical approaches, thus supporting the use of the latter in models. Furthermore, we hypothesized that MicN production in scenarios that are notably different from average would be better predicted by more mechanistic prediction approaches.

\section{MATERIALS AND METHODS}

\section{Data Collection and Preparation}

Data were collected and prepared for analysis as described in Roman-Garcia et al. (2016). Briefly, a literature search was conducted to identify studies that measured duodenal or omasal $\mathrm{N}$ flows. A total of 183 studies (613 treatments) were collected from the available literature. Most studies reported the inclusion rates of the ingredients used in diets; however, few studies reported nutrient composition of all ingredients. When ingredient nutrient composition data were available, they were used to calculate dietary nutrient provision. When ingredient-level data were not available, data were filled in from the NRC (2001) feed table. To minimize bias from incorrectly specifying ingredients, the study-level nutrient residuals were calculated and used to adjust book values to ensure no mean bias within a study, as described in Hanigan et al. (2013). Means and standard errors were collected for all response variables of interest, and when standard errors were not directly reported, calculated using error propagation (RomanGarcia et al., 2016).

\section{Microbial N Models and Model Derivation Procedure}

Three estimates of MicN production were derived in a companion paper (Roman-Garcia et al., 2016). Models were based on diet (Equation [1]), ruminal carbohydrate digestibility (Equation [2]), or microbial efficiency (EMPS; Equation [3]):

$$
\begin{aligned}
\text { MicN }=-18.3+109.0 \times \text { Omasal }+10.8 \times \mathrm{DMI}+5.31 \\
\times \text { Starch }-0.0839 \times \text { Starch }^{2}, \\
\text { MicN }=-52.1+122 \times \text { Omasal }+12.5 \times \mathrm{DMI} \\
+1.23 \times \mathrm{dStarch}+2.23 \times \frac{\mathrm{dStarch}}{\mathrm{dNDF}}, \\
\text { MicN }=\left(\begin{array}{l}
43.4-1.27 \times \mathrm{DMI}+0.0342 \\
\times \mathrm{DMI}^{2}-0.110 \times \mathrm{NDF}
\end{array}\right) \\
\times \frac{\mathrm{dOM}}{100} \times \mathrm{DMI},
\end{aligned}
$$

where Omasal was a binary indicator holding a value of 1 if omasal sampling was used and 0 if duodenal samping was used, DMI was kilograms per day, Starch was diet starch (\% of DM), dStarch was ruminally digestible starch $(\mathrm{kg} / \mathrm{d})$, dNDF was ruminally digestible NDF $(\mathrm{kg} / \mathrm{d})$, and $\mathrm{dOM}$ was ruminally digestible $\mathrm{OM},(\mathrm{kg} / \mathrm{d})$. Starch and OM digestibilities were on an apparent basis. Fit statistics were calculated for the models (Equations [1], [2], and [3]; Table 1) assuming all variables were measured inputs, and plots of residuals are shown in Supplemental Figures S1, S2, and S3 (http://dx.doi.org/10.3168/jds.2015-10662).

\section{Derivation of Digestible Carbohydrate Equations}

To deploy Equation [2] or [3] in any normal model, a prediction of digestible starch, NDF, or OM would be essential. Rumen starch, NDF, and OM digestibilities 
Table 1. Comparison of statistical goodness of fit for each approach used to estimate microbial $\mathrm{N}$ flows

\begin{tabular}{lccc}
\hline Fit statistic & $\begin{array}{c}\text { Empirical } \\
(\text { Eq. 1) }\end{array}$ & $\begin{array}{c}\text { NDF/starch } \\
\text { digestibility } \\
\text { (Eq. 2) }\end{array}$ & $\begin{array}{c}\text { Microbial } \\
\text { efficiency } \\
\text { (Eq. 3) }\end{array}$ \\
\hline $\mathrm{N}^{2}$ & 156 & 156 & 156 \\
Observed mean & 304.3 & 304.3 & 304.3 \\
Predicted mean & 302.7 & 306.8 & 330.3 \\
RMSE, ${ }^{3}$ g/d & 73.4 & 73.4 & 80.6 \\
RMSE, \% mean & 24.2 & 24.0 & 24.4 \\
Mean bias, \% MSE & 0.051 & 0.107 & 10.3 \\
Slope bias, \% MSE & 0.177 & 0.441 & 0.900 \\
Mean bias, g/d & 1.66 & -2.42 & -25.9 \\
Slope bias, g/g & -0.058 & -0.089 & -0.142 \\
CCC & 0.50 & 0.50 & 0.43 \\
\hline
\end{tabular}

${ }^{1}$ Eq. = Equation.

${ }^{2} \mathrm{~N}=$ number of treatment means.

${ }^{3} \mathrm{RMSE}=$ root mean squared prediction error.

${ }^{4}$ Mean squared prediction error.

${ }^{5} \mathrm{CCC}=$ concordance correlation coefficient.

were available within the data set, and functions were fit to predict these variables. The fitting procedure was identical to that previously described and detailed in Roman-Garcia et al. (2016). That is, the functions were derived in a multi-phase stepwise manner in which parameters were eliminated due to nonsignificance and subsequently eliminated parameters were tested in the final model for improved model fit and parameter significance. The prediction of rumen NDF digestibility began with the model:

$$
\begin{aligned}
\mathrm{dNDF} & =\text { Omasal }+\mathrm{NDF}+\mathrm{NDF}^{2}+\text { Starch }+ \text { Starch }^{2} \\
& +\mathrm{CP}+\mathrm{CP}^{2}+\frac{\mathrm{ADF}}{\mathrm{NDF}} \times 100+\text { DMIDryFor } \\
& + \text { DMIWetFor }+\mathrm{DMI}+\mathrm{DMI}^{2}
\end{aligned}
$$

where Omasal was the class effect for sampling location, DMIDryFor was the percentage of dry forage in the diet, and DMIWetFor was the percentage of wet forage. After the sequential backward elimination procedure was performed, Omasal, $\mathrm{NDF}^{2}$, $\mathrm{Starch}^{2}$, DMIDryFor, and $\mathrm{DMI}^{2}$ were dropped from the model.

The initial equation tested to predict rumen starch digestibility was very similar:

$$
\begin{aligned}
& \mathrm{dStarch}=\text { Omasal }+\mathrm{NDF}+\mathrm{NDF}^{2}+\text { Starch }+\mathrm{Starch}^{2} \\
& +\mathrm{CP}+\mathrm{CP}^{2}+\text { DMIDryFor }+ \text { DMIWetFor }+\mathrm{DMI}+\mathrm{DMI}^{2} .
\end{aligned}
$$

Variables that were removed from the model during the backward elimination procedure included NDF, $\mathrm{NDF}^{2}$, $\mathrm{CP}, \mathrm{CP}^{2}$, DMIDryFor, and $\mathrm{DMI}^{2}$.
Roman-Garcia et al. (2016) also derived an equation for EMPS (Equation [3]). To use this model to predict MicN, an estimate of ruminal truly digestible OM was also derived:

$$
\begin{aligned}
\mathrm{dOM} & =\mathrm{DMI}+\mathrm{DMI}^{2}+\mathrm{NDF}+\mathrm{NDF}^{2}+\mathrm{Starch}+\mathrm{Starch}^{2} \\
& +\mathrm{CP}+\mathrm{CP}^{2}+\frac{\mathrm{ADF}}{\mathrm{NDF}} \times 100+\text { DMIWetFor } \\
& + \text { DMIDryFor. }
\end{aligned}
$$

During the fitting procedure, DMI, $\mathrm{DMI}^{2}, \mathrm{CP}, \mathrm{CP}^{2}$, and $\mathrm{ADF}$ to NDF ratio were removed due to nonsignificance.

Previous calculation schemes have relied on TDN to predict rumen MicN (NRC, 2001). However, TDN is based on total-tract digestibilities, which might misrepresent ruminally available nutrients, and weights digestible fat by 2.25 . To better understand potential errors attributable to site of digestion, equations for total-tract NDF (7), apparent starch (8), and apparent OM (9) digestibilities were also derived.

\section{Quantifying the Intake/Digestibility Feedback Loop}

An important and somewhat poorly understood feedback loop apparent in ruminant biology is that of DMI and digestibility. Increasing ruminal digestibility of NDF alleviates bulk fill restriction of DMI; in contrast, increasing DMI can increase ruminal passage rate and decrease digestibility (Firkins et al., 1998). Additionally, although DMI is typically an input into ration balancing systems, when these systems are augmented to predict animal requirements or animal responses, DMI is either assumed or predicted. Incorporating a model predicting DMI and accounting for the effect of predicting DMI on the accuracy and precision of the system of equations is important. During the fitting procedure, DMI, $\mathrm{DMI}^{2}, \mathrm{CP}, \mathrm{CP}^{2}$, and $\mathrm{ADF}$ to $\mathrm{NDF}$ ratio were removed due to nonsignificance. An empirical representation of DMI was included based on the starting model:

$$
\begin{aligned}
\mathrm{DMI} & =\mathrm{BW}+\mathrm{BW}^{2}+\mathrm{DIM}+\mathrm{DIM}^{2}+\mathrm{NDF}+\mathrm{NDF}^{2} \\
& +\mathrm{Starch}+\mathrm{Starch}^{2}+\mathrm{CP}+\mathrm{CP}^{2}+\mathrm{ForDMI} \\
& + \text { ForNDF }+\frac{\mathrm{ADF}}{\mathrm{NDF}}
\end{aligned}
$$

where ForDMI was forage percentage of DM, and forage NDF was the NDF percent coming from forage (\% of DM). During the fitting procedure, all terms except 
BW, DIM, DIM ${ }^{2}$, and NDF were dropped from the model due to nonsignificance.

To better evaluate the relationship between DMI and ruminal carbohydrate digestibility, a more complex DMI prediction equation was derived to include terms for ruminal starch and NDF digestibilities. Although this equation was impractical to use in estimating MicN because of the circular calculation structure, it did enable more robust evaluation of the factors influencing the DMI and digestibility relationship. The starting model included

$$
\begin{aligned}
& \mathrm{DMI}=\mathrm{BW}+\mathrm{BW}^{2}+\mathrm{DIM}+\mathrm{DIM}^{2}+\mathrm{NDF}+\mathrm{NDF}^{2} \\
& \quad+\mathrm{Starch}+\mathrm{Starch}^{2}+\mathrm{CP}+\mathrm{CP}^{2}+\text { ForDMI }+ \text { ForNDF } \\
& +\mathrm{ByNDF}+\mathrm{dStarch}+\mathrm{dNDF},
\end{aligned}
$$

and all parameters dropped from the model except BW, NDF, NDF ${ }^{2}$, byproduct NDF (ByNDF), ruminally digestible starch (dStarch), and ruminally digestible NDF (dNDF).

\section{Statistical Analysis}

All statistical analysis was completed in R v. 3.1 .0 ( $\mathrm{R}$ Core Team, 2014). Model derivation was completed using the lmer test package (Kuznetsova et al., 2013). All models had a random intercept effect for study in addition to a series of linear fixed effects. Data were weighted by the inverse of the standard error of the mean after standardizing standard error derived from fixed and mixed procedures as described in Roman-Garcia et al. (2016). Root estimated variance $\left(\hat{\sigma}_{e}\right)$, mean (unless evaluated with the same derivation data) and slope biases as percentages of estimated mean squared error, Lin's concordance correlation coefficient (CCC), corrected Akaike information criterion, and variance inflation factors (VIF) were used to evaluate all models (Hurvich and Tsai, 1989; Lin, 1989; Boerman et al., 2015). As discussed by Roman-Garcia et al. (2016), final models had VIF $\leq 10$ for all terms except potentially for squared or interaction terms, which are correlated by calculation and therefore had VIF $\leq 100$. Here, $\hat{\sigma}_{e}$ was used as an estimated root mean squared error (RMSE) that was congruent with the likelihoodbased estimation approach (rather than the leastsquares derivation that RMSE assumes) and accounted for residual error variance separately from variance explained by random study intercepts. In the evaluation of the equations presented in Roman-Garcia et al. (2016) against the truncated data subset that was identical for each equation, RMSE was calculated as the root of the average squared residual because the data used in evaluation were not identical to the derivation data sets and no random intercept effects were involved in the calculation of modeled values, making a leastsquares-based evaluation the most appropriate method.

Monte Carlo cross validation was performed to evaluate all models against independent data sets. During this cross-validation procedure, the data set was split so $70 \%$ of the treatments were used for model derivation and $30 \%$ of the data were used for model evaluation. The data splitting, model derivation, and model evaluation was repeated 1,000 times using unique strings of random numbers to identify which treatments were used for evaluation and which were used for evaluation. The root mean square prediction error (RMSPE) was recorded for each of the 1,000 model evaluations, and the mean and standard error of the RMSPE were used to compare models. Note that different abbreviations are used to indicate evaluation against independent data (RMSPE) and evaluation against derivation data (RMSE).

\section{Stochastic Analysis of Different Estimation Methods}

The differences between mechanistic and empirical modeling approaches extend beyond statistical goodness of fit. Mechanistic models have been proposed to have more bounded responses when input errors exist because the model complexity provides feedback that prevents prediction of extreme responses. Empirical models, however, are highly influenced by input errors (White et al., 2015) because their calculation structure is not conducive to offsetting random errors in inputs.

Variance in input parameters (DMI, NDF, starch, ByNDF, ForNDF, DMIWetFor, DMIDryFor, CP, and $\mathrm{ADF}$ ) were simulated by generating a multi-variate random normal distribution reflective of input measurement errors. Generating input errors in this manner offers a unique opportunity to better account for the covariation among inputs and allows for more grounded analysis of the sensitivity of the models. The mean of each vector within the distribution was assigned a value of 0 ( $0 \%$ different from true mean) assuming measurements were correct on average. A correlation matrix was calculated on mean difference values (MD):

$$
\mathrm{MD}_{\text {in }}=\frac{i-\bar{i}}{\bar{i}},
$$

where $i$ was an individual observation and $\bar{i}$ was the mean observation in the data set. Mean difference for an input $\left(\mathrm{MD}_{\text {in }}\right)$ were used to account for the difference between an observation and a baseline, which is more reflective of correlations in measurement errors than 
correlations obtained from absolute values. Variance estimates for each of the inputs were used to define the average range in differences from the true mean measurement. The errors were estimated from SE presented in large feed libraries (https://nanp-nrsp-9.org/feed/ search/ or http://dairyone.com/analytical-services/ feed-and-forage/feed-composition-library/). The correlation matrix and variance estimates used to develop the data set are specified in Table 2. From this distribution, 10,000 draws were simulated for each available MicN measurement. For each draw, the value of each input parameter was adjusted $\left(\mathrm{In}_{\mathrm{ad}}\right)$ based on the randomly generated difference from the mean:

$$
\operatorname{In}_{\mathrm{ad}}=\left(1+\mathrm{MD}_{\mathrm{in}}\right) \times \mathrm{In},
$$

where inputs were measured observations required to predict MicN (NDF \% DM, wet forage DM, byproduct NDF, and so on). Equations [1], [2], and [3] were used to predict MicN for each of the 10,000 input parameter combinations, and residuals were calculated. In the "known DMI" scenarios, DMI reported in each study was included as a known value and digestible NDF, starch, and $\mathrm{OM}$ were predicted by Equations [4], [5], and [6]. In the "predicted DMI" scenarios, DMI was also predicted by Equation [10]. The mean and standard deviation of the residuals for each calculation approach were evaluated to identify the durability of the equations in the presence of input parameter variability.

\section{Extreme Scenario Testing}

Mechanistic models are proposed to have improved capacity to replicate biology during extreme scenarios from which empirical estimations may be extrapolated (Ford, 2009). Extreme scenario testing was used to evaluate whether the more mechanistic predictions had improved prediction accuracy on data subsets representing the tails of the distribution of available data. Subsets of the available data were generated to return the highest $25 \%$ of (1) BW, (2) DMI, (3) forage percentage of DMI, and (4) starch percentage of DMI. Each of the models, Equations [1], [2], and [3], were used to predict MicN from measurements available in those data sets. For each data subset, estimated RMSE and $\mathrm{CCC}$ were calculated based on predictions from each equation. The statistical goodness of fit was compared across models to determine advantages of each approach in different feeding situations.

\section{RESULTS AND DISCUSSION}

\section{Statistical Goodness of Fit for Microbial N Estimation Methods}

When compared on an identical data set (a subset of the derivation data), Equations [1] and [2] returned the lowest RMSE, highest CCC, and smallest mean or slope bias of the 3 methods compared (Table 1). Although incorporating more biologically interpretable inputs, Equation [2] did not perform any better than a simple, diet-based empirical prediction. This minimal difference between calculation methods suggests that minimal benefit is achieved from including measurements of rumen carbohydrate digestibility in estimates of $\mathrm{MicN}$ when compared strictly based on fit to the derivation database. Monte Carlo cross-validation indicated that RMSPE for Equation [1] was favorable (lower RMSPE and lower SE) in comparison with Equations [2] and [3] (Table 3). Given the highly empirical nature of Equation [1], this equation was expected to have improved accuracy and precision when compared with the more mechanistic approaches.

\section{Rumen and Total-Tract Digestibilities}

The models of rumen starch, NDF, and OM digestibilities derived in this study are presented in Table 4, and residuals are shown in Supplemental Figures S4 to

Table 2. Correlation between input parameters with standard errors assumed in predicting inputs (\% mean) along the diagonal

\begin{tabular}{|c|c|c|c|c|c|c|c|c|c|}
\hline Item & DMI & NDF & Starch & $\begin{array}{l}\text { Forage } \\
\mathrm{NDF}\end{array}$ & $\begin{array}{l}\text { Byproduct } \\
\text { NDF }\end{array}$ & $\begin{array}{l}\text { Wet forage } \\
\text { DMI }\end{array}$ & $\mathrm{CP}$ & $\mathrm{ADF}$ & $\begin{array}{c}\text { Dry forage } \\
\text { DMI }\end{array}$ \\
\hline DMI & $15^{1}$ & & & & & & & & \\
\hline NDF & -0.303 & 5.08 & & & & & & & \\
\hline Forage NDF & 0.516 & -0.081 & -0.396 & 5.5 & & & & & \\
\hline Byproduct NDF & $-0.241^{2}$ & 0.475 & -0.177 & -0.408 & 6.0 & & & & \\
\hline Wet forage DMI & 0.434 & -0.229 & $0.102^{2}$ & 0.653 & -0.487 & 15 & & & \\
\hline
\end{tabular}

${ }^{1}$ Standard deviations used in analysis are presented along the diagonal, and correlations are presented in corresponding cells below.

${ }^{2}$ Correlation coefficient not different from $0(P>0.05)$. 
S8 (http://dx.doi.org/10.3168/jds.2015-10662). Rumen NDF digestibility was significantly affected by NDF, starch, CP, ADF to NDF ratio, wet forage percent in the diet, and DMI. Previous work has identified a relationship between the ratio of potentially digestible NDF (NDF minus indigestible NDF) to dietary NDF and ruminal NDF digestibility (Huhtanen et al., 2009). Here, the ADF to NDF ratio was used as a metric of diet indigestibility as an indicator of forage type. Unique ADF to NDF ratios have been identified for corn silage, grass forage, and legume forage (NRC, 2001), supporting the relationship between forage type, diet indigestibility, $\mathrm{ADF}$, and NDF. Legumes and grasses have different dynamics in the rumen because more fragile legumes are readily degraded and break down into particles that more readily pass the rumen compared with grasses (Kammes and Allen, 2012). These forage types also have differing ADF to NDF ratios (Palmonari et al., 2016), so the ADF to NDF ratio is a convenient way of assessing digestibility differences between grasses and legumes. The significance of the parameter estimate supports ADF to NDF ratio as an appropriate method of accounting for these differences among forage types, particularly when they are of heterogeneous mixtures.

The primary differences between ruminal and totaltract NDF digestibility predictions (Equations [4] and [7]) was the significance of the $\mathrm{CP}$ and $\mathrm{ADF} / \mathrm{NDF}$ terms in the rumen digestibility model. These differences were unexpected because postruminal digestion of NDF was assumed to be responsible for a relatively small proportion of total-tract digestibility (Gressley et al., 2011). The lack of significance of the ADF/NDF and $\mathrm{CP}$ terms in the total-tract NDF digestibility model suggests that compensatory digestibility of fiber occurs in the hindgut (Merchen et al., 1997) and factors such as available $\mathrm{N}$ and forage type (ADF/NDF) are more important for predicting ruminal digestibility than total-tract digestibility. In contrast with ruminal and

Table 3. Model fit statistics estimated from cross validation

\begin{tabular}{lcc}
\hline Model & RMSPE $^{1}$ & $\mathrm{SE}$ \\
\hline Eq. $1^{2}$ & 21.9 & 2.5 \\
Eq. 2 & 25.6 & 3.2 \\
Eq. 3 & 29.2 & 1.7 \\
Eq. 4 & 25.2 & 2.2 \\
Eq. 5 & 27.8 & 2.0 \\
Eq. 6 & 41.8 & 15.6 \\
Eq. 7 & 21.5 & 2.2 \\
Eq. 8 & 5.8 & 0.63 \\
Eq. 9 & 5.0 & 0.43 \\
Eq. 10 & 8.8 & 0.81 \\
Eq. 11 & 7.4 & 0.83 \\
\hline
\end{tabular}

${ }^{1} \mathrm{RMSPE}=$ root mean squared prediction error obtained from repeated evaluation against independent data.

${ }^{2}$ Eq. $=$ Equation. total tract NDF digestibilities, though, ADF/NDF did not remain in the final model for true ruminal OM digestibility (Equation [6]) but did remain for total-tract OM digestibility (Equation [9]). Predictor variables are correlated (Table 2), probably explaining part of the interchanging of variables among equations. Although microbial populations in the rumen and hindgut have similar physiological capacity for carbohydrate degradation (Nolan, 1975; Stevens et al., 1980), the hindgut microbes only have access to what was not digested by the rumen microbes. Additionally, passage rate of particles from the hindgut is increased when compared with the rumen (Vanhatalo and Ketoja, 1995; Wylie et al., 2000; Yang et al., 2002).

Previous work has demonstrated that ruminal starch digestibility is significantly affected by grain type (Ferraretto et al., 2013), processing method (Offner et al., 2003), silage processing (Ferraretto and Shaver, 2012), and starch vitreousness (Philippeau et al., 2000). In this analysis, ruminal starch digestibility was significantly affected by sampling location, DMI, forage NDF, starch, and wet forage inclusion rate (Table 4). Apparent ruminal starch digestibility increased at a decreasing rate as dietary starch concentration increased. This might have been reflective of increasing rates of grain inclusion in the diet, which likely increased availability of readily fermentable starches. The significance of the wet forage inclusion rate parameter is likely indicative of a corn silage effect because corn silage was the primary wet forage included in the data set. Older studies might poorly represent the ruminal digestibility of starch in corn silage because the corn grain in the silage might have been insufficiently processed. A large body of work has identified that increasing dietary starch concentration (and thereby increasing starch digestibility) can depress forage fiber degradation (Mould et al., 1983; Grant, 1994; Dixon and Stockdale, 1999), and no simple solutions (such as depressed $\mathrm{pH}$ ) can mechanistically explain these negative associative effects (Firkins and $\mathrm{Yu}, 2015$ ). The diet NDF term dropped from the rumen starch digestibility model derived herein likely because of the high negative correlation between diet NDF and diet starch percentages (Roman-Garcia et al., 2016). The term for forage NDF suggested that, as forage NDF increased, starch digestibility also increased. This is somewhat paradoxical given the well-documented relationship between diet NDF and starch digestibility; however, it might be representing improved retention of microbial species in the rumen associated with a more developed fiber mat. Linear associations between ruminal starch digestibility and dietary forage concentration have previously been reported (Ranathunga et al., 2013), and further work has demonstrated that relationships 
WHITE ET AL.

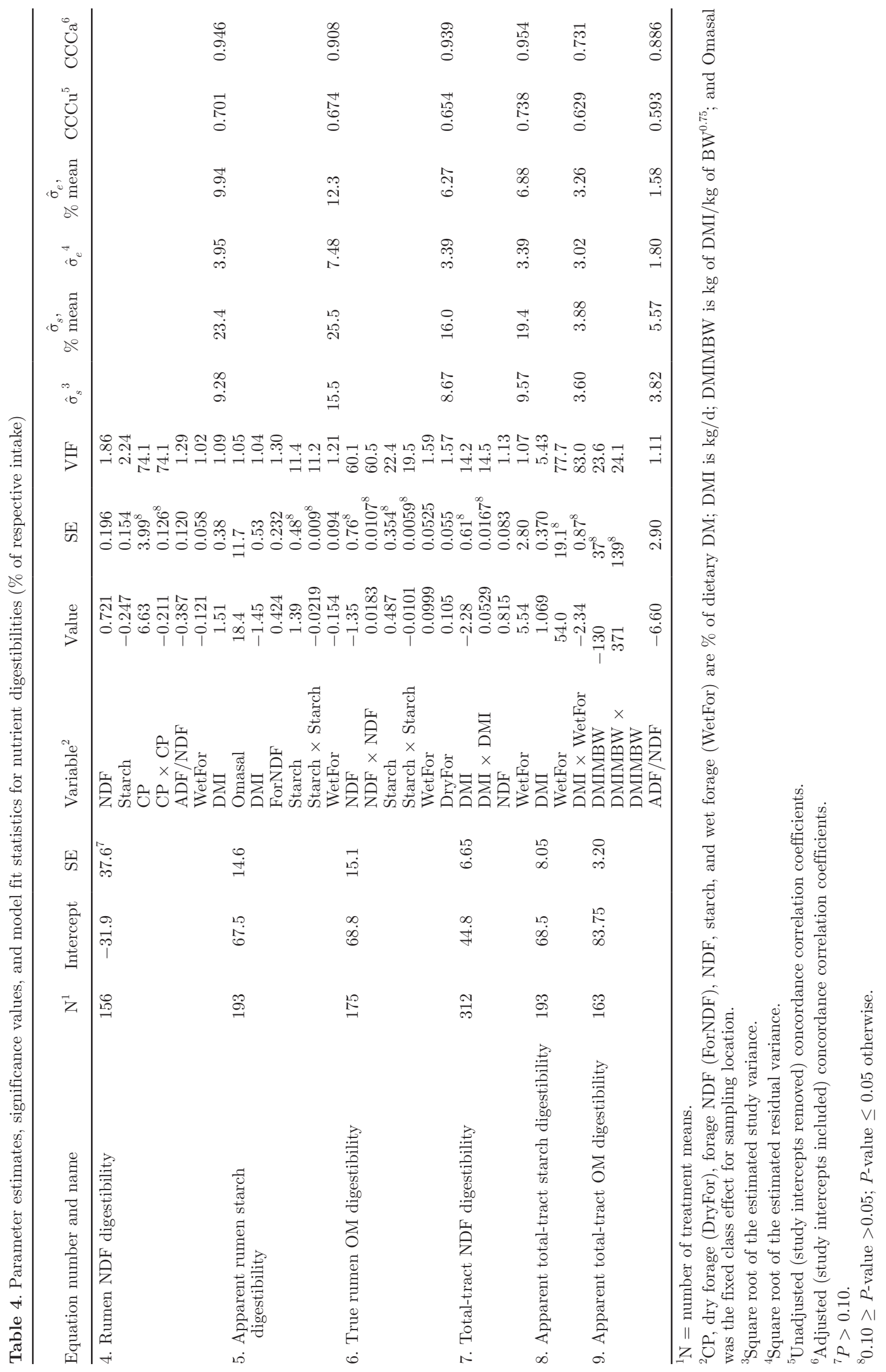


between ruminal starch and fiber digestibility interact with DMI (Lopes et al., 2015). The forage NDF term in this model might be indicative of a larger DMI effect whereby negative effects of increasing DMI on starch digestibility are partially abated when greater quantities of forage NDF are available in the diet. Firkins et al. (2001) noted that both forage percentage and DMI were negatively associated with apparent ruminal starch digestibility. This potential interaction is further supported by the total-tract starch digestibility model in which total-tract starch digestibility was affected by DMI, wet forage percentage, and their interaction.

Previous meta-analysis of rumen OM digestibility suggested that DMI, CP, silage type, and concentrate fat intake affects rumen OM digestibility (Huhtanen et al., 2009). The rumen apparent OM digestibility model derived herein (Table 4) was poorly identifiable because many of the parameter estimates only tended toward significance. The model suggested that fermentable OM decreased with increasing NDF at an increasing rate but increased with diet starch percentage at a decreasing rate. Starch and NDF percentages are inversely correlated in most diets; consequently, the resulting effect of these parameters on rumen OM digestibility offsets considerably. Both wet and dry forage increased apparent rumen OM digestibility. Many studies used in this data set tested various byproduct feeds and replaced forage NDF with byproduct NDF. This replacement is associated with decreased NDF digestibility (Firkins, 1997), which undoubtedly contributes to reduced OM digestibility.

\section{Intake and Digestibility Feedback Loops}

A major challenge in deriving equations for use in empirical ration balancing systems is the prediction of voluntary intake and the correlations between intake and digestibility. Several theories regarding regulation of DMI in ruminants suggest that intake is regulated by NDF digestibility and starch fermentation, among other factors (Allen et al., 2009). Although numerous equations predicting DMI have been derived (Krizsan et al., 2014), few have explicitly addressed the circular calculation issue surrounding intake and ruminal carbohydrate digestibility. Arguably, DMI equations should have an effect for degradability of NDF and starch. More digestible forages with increased fragility (especially legumes compared with grasses) have faster comminution and alleviate rumen fill by faster degradation or passage. Longer, less fragile forages (especially grasses) probably entrap and slow passage of potentially passable pools, maintain fill, and lengthen the intermeal interval (Kammes and Allen, 2012). However, the argument can also be made to predict NDF and starch digestibilities as a function of DMI because increasing DMI decreases ruminal digestibility through faster passage rates (Firkins et al., 1986; Murphy et al., 1994).

Although a DMI equation independent of rumen carbohydrate digestibility was derived to avoid this circular calculation issue, we also derived an equation that predicted DMI as a function of ruminal nutrient digestibility (Table 5). Residual plots of the DMI equations are included in Supplemental Figures S6 and S7 (http://dx.doi.org/10.3168/jds.2015-10662). Intake was predicted to increase with increasing ruminally digestible NDF and starch. These modeled relationships support the assumption that reducing gut fill through improved digestion stimulates DMI. Including terms for NDF and starch digestibilities notably improved fit statistics of the DMI models, resulting in an 8 percentage unit increase in unadjusted CCC. This suggests that equations predicting DMI should include terms for the predicted ruminal digestibility of carbohydrate within the diet. As previously noted, this scenario is also problematic because it requires a circular calculation in which ruminal carbohydrate digestibility affects DMI and is affected by DMI. A more mechanistic solution suggests that nutrients are digested with respect to time and DMI, and satiety signals occur as a function of feedback from digestion (Gregorini et al., 2013). An empirical alternative is to remove one relationship from the system to enable calculation. In this case, ruminal digestibility effects on DMI were removed because removing DMI from the ruminal digestibility equations caused the fitting procedure to become unstable, and the goodness of fit was reduced. Although calculating DMI without rumen digestibility effects was sufficient for this exercise based on equations derived (Table 5) and fit (Supplemental Figures S9 and S10; http:// dx.doi.org/10.3168/jds.2015-10662), future work should attempt to find a more applicable method of integrating the circular DMI and digestibility relationships into empirical models.

\section{Comparison of Empirical and Mechanistic Estimation Procedures}

Goodness of Fit. Empirical and mechanistic models have been used extensively to predict microbial protein flow (Dijkstra et al., 1998). Although often thought of as distinct model types, these 2 descriptors represent a spectrum of modeling objectives, methods, and physical structures (Baldwin, 1995). Mechanistic systems (Hanigan et al., 2013; Ghimire et al., 2014; Gregorini et al., 2015) make up one side of the spectrum, and empirical predictions (Huhtanen and Hristov, 2009; Broderick et al., 2010) make up the other side. Ration balancing systems such as the Cornell Net Carbohydrate and 


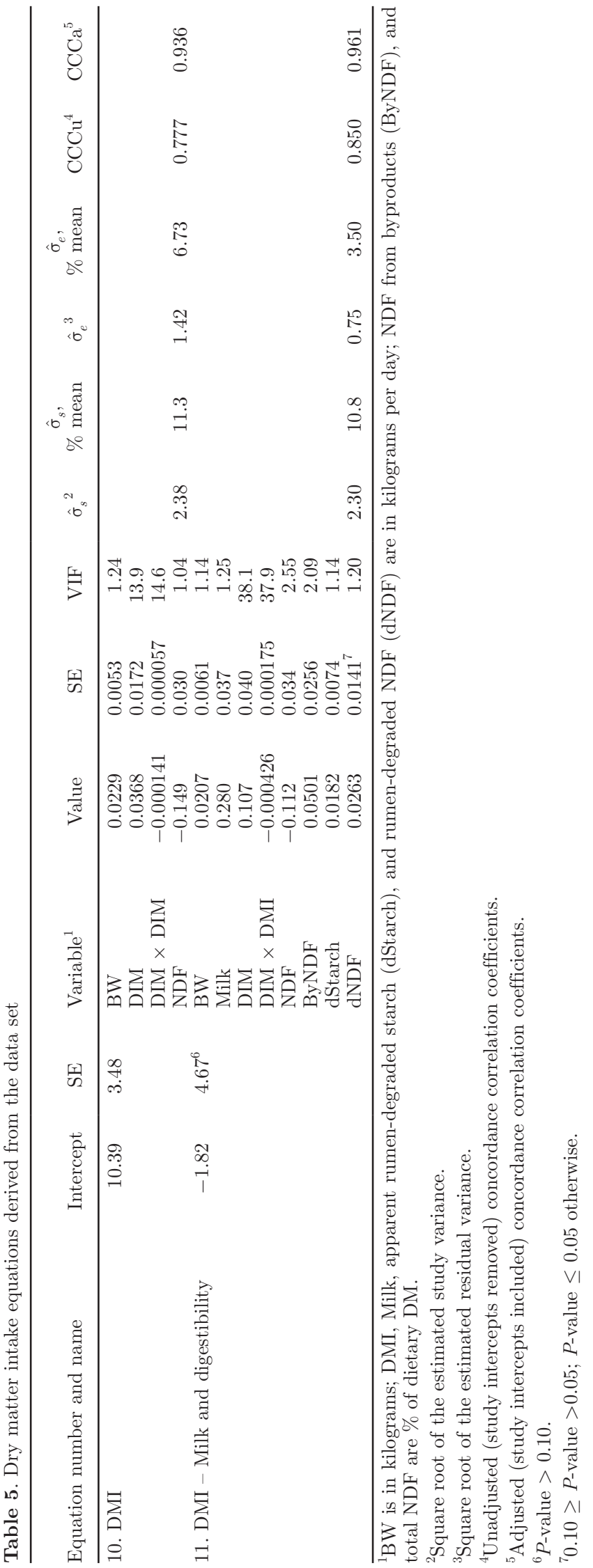

Protein System (Fox et al., 2004; Van Amburgh et al., 2015) and some components of the NRC (2001) can be described as partially mechanistic and exist somewhere in the middle. Although both mechanistic and empirical approaches have merit and unique benefits, comparisons of mechanistic and empirical models are usually limited to evaluating accuracy and precision. Residual plots for the different microbial $\mathrm{N}$ prediction approaches are included in Supplemental Figures S8 to S10 (http://dx.doi.org/10.3168/jds.2015-10662).

To understand tradeoffs in model accuracy and precision, Equations [1], [2], and [3] were evaluated against a common data set from which digestible NDF (Equation [4]), starch (Equation [5]), and OM (Equation [6]) were predicted in all scenarios. To evaluate a more mechanistic prediction, DMI (Equation [10]) was predicted in half the scenarios (Table 6). Irrespective of DMI prediction, the fit statistics for the empirical prediction approach were almost identical to the more complex rumen-degraded carbohydrate prediction system and were more precise and more accurate than the EMPS equation. Given the proposed benefits of more empirical calculation, high precision and accuracy of the empirical approach was anticipated. Unexpectedly, the ruminal carbohydrate digestibility-based approach also had favorable fit statistics, and the comparison between the empirical calculation approach and the calculation based on ruminal carbohydrate digestibility suggests that accuracy and precision are not compromised when predicting microbial protein based on rumen digestible carbohydrate. Although using EMPS to predict microbial $\mathrm{N}$ has been proposed as a beneficial strategy (Russell et al., 1992), the EMPS-based prediction did not have favorable fit statistics, which is consistent with previous attempts (Firkins et al., 1998).

The cross-validation procedure also favored the empirical microbial $\mathrm{N}$ equation because this approach had the lowest RMSPE and smallest standard error of any microbial $\mathrm{N}$ prediction. Although differences between Equations [1] and [2] were not identified when compared with the derivation data set, Equation [1] did have a slight advantage in RMSPE and SE when repeatedly evaluated against independent data. The similarities in fit statistics between Equations [1] and [2] were surprising. Equation [1] was limited in that it only related microbial $\mathrm{N}$ to starch and DMI, whereas Equation [2] related microbial $\mathrm{N}$ to starch, DMI, NDF, $\mathrm{CP}, \mathrm{ADF}$ to NDF ratio, and wet forage percentage. The difference in explanatory variables might suggest that Equation [1] was missing information associated with these additional sources of variation or that Equation [2] covers the same relationships as Equation [1] (using different but correlated explanatory variables) and supports Equation [1] as a robust prediction across dietary 
Table 6. Statistical comparison the means and SD of microbial N equations simulated with measured or modeled DMI

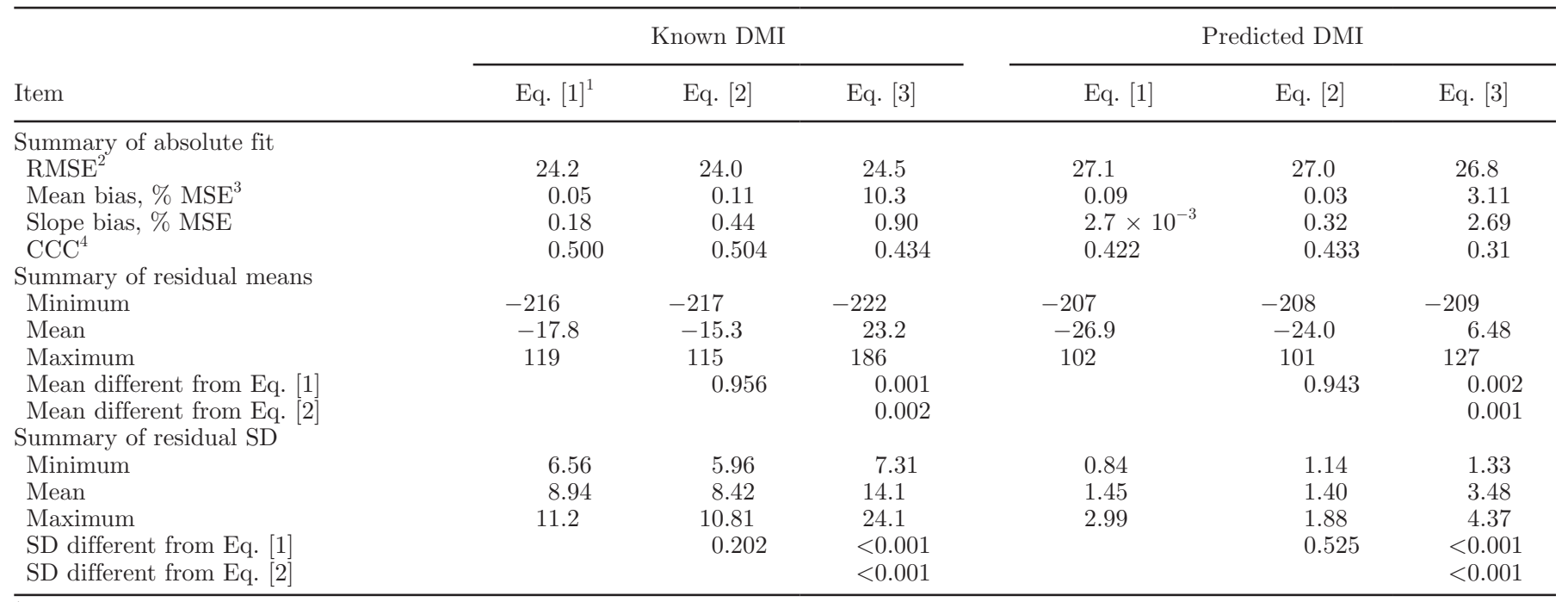

${ }^{1}$ Eq. = Equation.

${ }^{2}$ Root mean squared prediction error.

${ }^{3}$ Mean squared prediction error.

${ }^{4}$ Concordance correlation coefficient.

conditions. When considered together and comparing their residuals plots (Supplemental Figures S1 and S2; http://dx.doi.org/10.3168/jds.2015-10662), the equations support use of either more mechanistic (Equation [2]) or empirical (Equation [1]) approaches to predicting microbial N.

Residual Precision and Accuracy. Stochastic model evaluation is gaining popularity as a means of understanding the error bounds around a simulation or prediction equation (Robert and Casella, 2013). In this analysis, we use stochastic evaluation to assess how the mean and standard deviation of a distribution of residuals vary by model method. A shift in mean residuals would suggest that the model average is sensitive to input errors, whereas a shift in the standard deviation of the residuals suggests that the overall model error is sensitive to input errors.

The mean residuals of Equations [1] and [2] did not differ from each other $(P>0.10)$ but were both different from the mean residuals of Equation [3] (Table 6). In general, the mean residual of Equation [3] was more sensitive to input errors than Equation [1] or [2]. A primary cause of this mean bias (Supplemental Figure S3; http://dx.doi.org/10.3168/jds.2015-10662) might be the lack of a term to account for sampling location. As discussed in Roman-Garcia et al. (2016), omasal sampling caused an intercept shift in measured MicN, returning notably higher estimates of $\mathrm{N}$ flows than those from duodenal sampling. Because Equation [3] did not explicitly account for this difference, predictions from this model represent a rough average of the 2 sampling methods and therefore the slopes in this model may be overly sensitive to factors that co-vary with sampling location such as DMI or starch percentage.

The consistency of Equations [1] and [2] agreed with the fit statistics analysis and was unexpected given the increased complexity of the model based on rumen NDF and apparent starch digestibilities. Although minimal mean or slope bias was detected in the models of digestible NDF or starch, both equations had $\hat{\sigma}_{e}$ of greater than $20 \%$ of the mean. Although $\hat{\sigma}_{e}$ in that range are fairly standard for empirical models, the error in predicting ruminally digestible NDF or starch should aggregate when these predictions were used as inputs to the MicN equation. The consistency in mean residuals suggests that no appreciable bias was introduced by predicting ruminal NDF and apparent starch digestibilities compared with predicting MicN based on measured diet variables and that both methods were equally capable of dealing with feed input variability.

The differences between the modeling approaches were consistent when DMI was measured or predicted (Table 6). Rather paradoxically, including a DMI prediction improved the precision of the residuals of all models. The structure of the stochastic analysis accounted for the correlations between parameter inputs. The correlations between the input values and correlations between equation parameter estimates might be compensating if increasing the number of parameters in the equation actually offset errors and improved precision of the response. Because no difference was present in the accuracy (mean residual) and precision (residual 
SD) of Equations [1] and [2], the approaches appear to be equally reliable methods of predicting MicN.

Extreme Scenario Testing. One proposed benefit of mechanistic models is the ability to behave more realistically in extreme scenarios. In the extreme scenarios tested in this evaluation, the empirical function (Equation [1]) and the function based on rumen carbohydrate digestibility (Equation [2]) performed consistently better than Equation [3] (Figure 1). This was unexpected. Because the range of values used in the extreme scenario testing did not exceed the range of values in the model derivation data set, the scenarios might not have been extreme enough to reveal benefits of a more mechanistic approach.
Although Equation [3] did not perform as well as the other calculation methods, it was more comparable on the high BW and high starch data sets. This comparison suggests that Equation [3] might have improved ability to represent high-producing cows with larger BW and greater DMI. Previous equations predicting EMPS have yielded similar accuracies as those predicting MicN directly (Broderick et al., 2010). The improved ability to predict MicN at high BW and DMI can be traced back to the accounting for omasal sampling techniques. Most studies employing omasal sampling were conducted in recent years, with lactating cows at higher DMI and very minimal variation in NEL concentration when compared with the variation in the duodenal

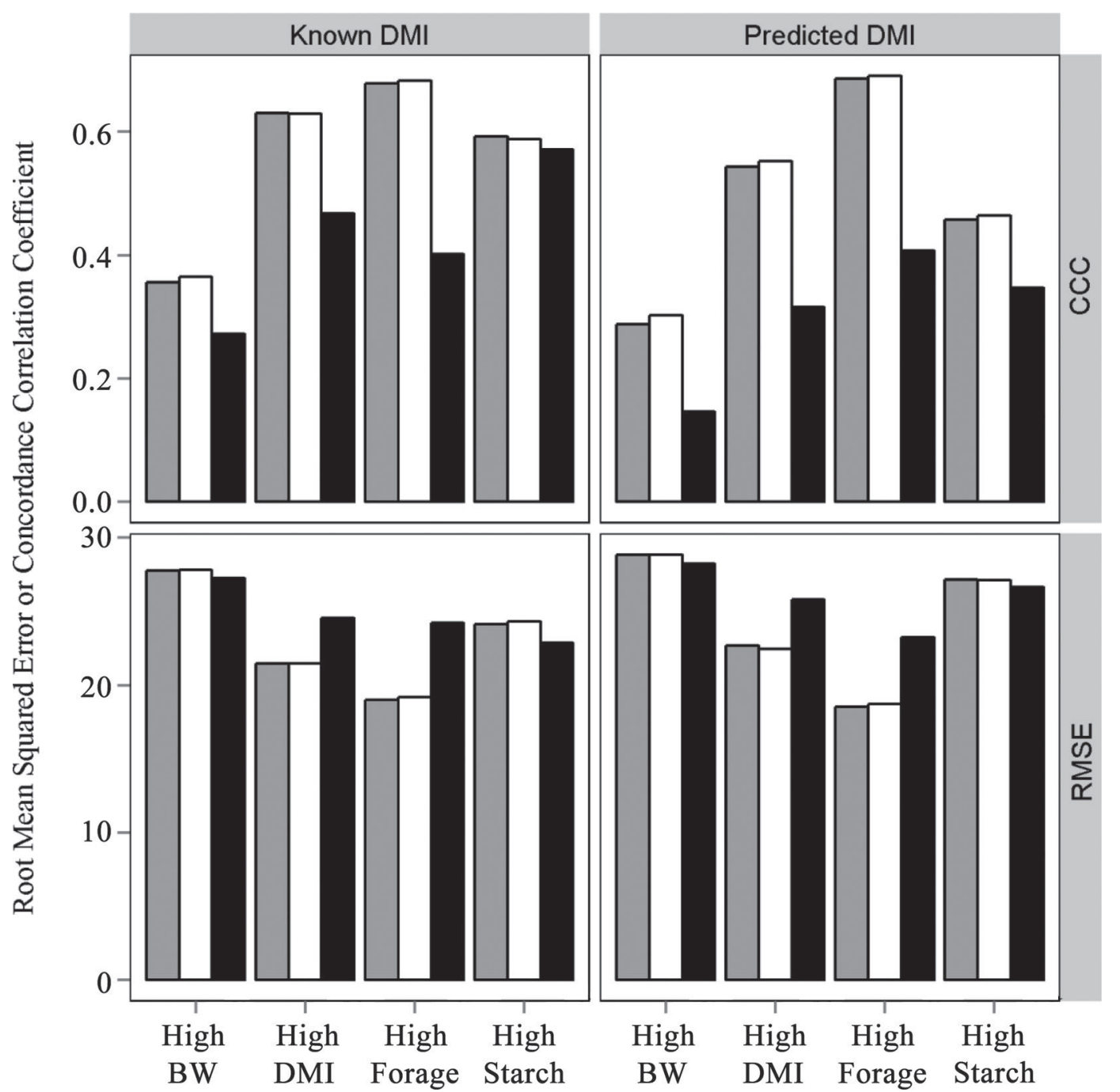

Figure 1. Comparison of fit statistics derived from the empirical equation (Equation [1]; gray bars), or the mechanistic equation systems relying on either predicting digestibility (Equation [2]; white bars) or predicting microbial efficiency (Equation [3]; black bars). Data sets representing high forage, high starch, high intake, and high BW were compiled for comparison. Dry matter intake was either assumed to be known or predicted. $\mathrm{CCC}=$ concordance correlation coefficient; RMSE $=$ root mean squared prediction error. 
sampling data. As such, the averaging between omasal and duodenal studies might help account for some variability attributable to animals with greater genetic potential. Overall, the differences between the prediction approaches were small from a practical perspective (RMSE varied by $<5 \%$ ) and might merely be artifacts of the data, rather than a reproducible biological phenomenon. Further evaluation of the interrelationships between high genetic potential for milk production, digestibility of nutrients, and EMPS is needed to better evaluate potential interrelationships.

\section{CONCLUSIONS}

The objectives of this study were to derive equations describing starch, fiber, and OM ruminal and totaltract $\mathrm{OM}$ digestibilities; use these equations as inputs to equations predicting $\mathrm{MicN}$ production; and evaluate the implications of the different calculation methods in terms of their precision and accuracy. Differences were identified among total-tract and rumen digestibility models, which supports future work evaluating predictions of hindgut digestibility. Dry matter intake was predicted by ruminal carbohydrate digestibility, but additional work modeling the interrelationship between DMI and digestibility is needed before this relationship can be incorporated into models estimating rumen carbohydrate digestibility. When compared against an identical data set, predicting microbial protein empirically had the lowest prediction error and highest concordance of any approach. Minimal differences were observed between empirical microbial protein prediction and microbial protein prediction from rumen carbohydrate digestibility in the stochastic analysis. Extreme scenario testing favored empirical and rumen digestibility-based microbial protein prediction in all scenarios. Despite the hypothesized benefits of a more mechanistic prediction approach, few differences could be identified between the empirical prediction and the equation relying on rumen carbohydrate digestibility.

\section{ACKNOWLEDGMENTS}

This work was carried out and supported, partially, as an activity of the National Animal Nutrition Program (NANP) to provide enabling technologies, support, and shared resources to the research community. The NANP, a National Research Support Project (NRSP-9) of State Agricultural Experiment Stations, is funded from Hatch funds administered by the National Institute of Food and Agriculture, USDA, Washington, DC. Research was supported by state and federal funds appropriated to the Ohio Agricultural Research and
Development Center, The Ohio State University. This is Manuscript number 11/16AS.

\section{REFERENCES}

Allen, M., B. Bradford, and M. Oba. 2009. Board-Invited Review: The hepatic oxidation theory of the control of feed intake and its application to ruminants. J. Anim. Sci. 87:3317-3334.

Baldwin, R. L. 1995. Modeling Ruminant Digestion and Metabolism. Vol. 1. Chapman and Hall, London, UK.

Bateman, H., J. Clark, R. Patton, C. Peel, and C. Schwab. 2001. Accuracy and precision of computer models to predict passage of crude protein and amino acids to the duodenum of lactating cows. J. Dairy Sci. 84:649-664.

Boerman, J., J. Firkins, N. St-Pierre, and A. Lock. 2015. Intestinal digestibility of long-chain fatty acids in lactating dairy cows: A meta-analysis and meta-regression. J. Dairy Sci. 98:8889-8903.

Broderick, G., P. Huhtanen, S. Ahvenjarvi, S. Reynal, and K. Shingfield. 2010. Quantifying ruminal nitrogen metabolism using the omasal sampling technique in cattle-A meta-analysis. J. Dairy Sci. 93:3216-3230.

Dijkstra, J., J. France, and D. R. Davies. 1998. Different mathematical approaches to estimating microbial protein supply in ruminants. J. Dairy Sci. 81:3370-3384.

Dixon, R., and C. Stockdale. 1999. Associative effects between forages and grains: Consequences for feed utilisation. Crop Pasture Sci. 50:757-774.

Ferraretto, L., P. Crump, and R. Shaver. 2013. Effect of cereal grain type and corn grain harvesting and processing methods on intake, digestion, and milk production by dairy cows through a metaanalysis. J. Dairy Sci. 96:533-550.

Ferraretto, L., and R. Shaver. 2012. Meta-analysis: Effect of corn silage harvest practices on intake, digestion, and milk production by dairy cows. Prof. Anim. Sci. 28:141-149.

Firkins, J., M. Allen, B. Oldick, and N. St-Pierre. 1998. Modeling ruminal digestibility of carbohydrates and microbial protein flow to the duodenum. J. Dairy Sci. 81:3350-3369.

Firkins, J., L. Berger, N. Merchen, and G. Fahey. 1986. Effects of forage particle size, level of feed intake and supplemental protein degradability on microbial protein synthesis and site of nutrient digestion in steers. J. Anim. Sci. 62:1081-1094.

Firkins, J., M. Eastridge, N. St-Pierre, and S. Noftsger. 2001. Effects of grain variability and processing on starch utilization by lactating dairy cattle. J. Anim. Sci. 79(E. Suppl.):E218-E238.

Firkins, J., and Z. Yu. 2015. Ruminant Nutrition Symposium: How to use data on the rumen microbiome to improve our understanding of ruminant nutrition. J. Anim. Sci. 93:1450-1470.

Firkins, J. 1997. Effects of feeding nonforage fiber sources on site of fiber digestion. J. Dairy Sci. 80:1426-1437.

Ford, A. 2009. Modeling the Environment. Vol. 2. Island Press Publishing, Washington, DC.

Fox, D. G., L. O. Tedeschi, T. P. Tylutki, J. B. Russell, M. E. Van Amburgh, L. E. Chase, A. N. Pell, and T. R. Overton. 2004. The Cornell Net Carbohydrate and Protein System model for evaluating herd nutrition and nutrient excretion. Anim. Feed Sci. Technol. 112:29-78.

Ghimire, S., P. Gregorini, and M. Hanigan. 2014. Evaluation of predictions of volatile fatty acid production rates by the Molly cow model. J. Dairy Sci. 97:354-362.

Grant, R. 1994. Influence of corn and sorghum starch on the in vitro kinetics of forage fiber digestion. J. Dairy Sci. 77:1563-1569.

Gregorini, P., P. Beukes, G. Waghorn, D. Pacheco, and M. D. Hanigan. 2015. Development of an improved representation of rumen digesta outflow in a mechanistic and dynamic model of a dairy cow, Molly. Ecol. Modell. 313:293-306.

Gregorini, P., P. C. Beukes, A. J. Romera, G. Levy, and M. D. Hanigan. 2013. A model of diurnal grazing patterns and herbage intake of a dairy cow, MINDY: Model description. Ecol. Modell. 270:11-29. 
Gressley, T., M. B. Hall, and L. Armentano. 2011. Ruminant Nutrition Symposium: Productivity, digestion, and health responses to hindgut acidosis in ruminants. J. Anim. Sci. 89:1120-1130.

Hanigan, M., J. Appuhamy, and P. Gregorini. 2013. Revised digestive parameter estimates for the Molly cow model. J. Dairy Sci. 96:3867-3885.

Huhtanen, P., and A. N. Hristov. 2009. A meta-analysis of the effects of dietary protein concentration and degradability on milk protein yield and milk $\mathrm{N}$ efficiency in dairy cows. J. Dairy Sci. 92:3222-3232.

Huhtanen, P., M. Rinne, and J. Nousiainen. 2009. A meta-analysis of feed digestion in dairy cows. 2. The effects of feeding level and diet composition on digestibility. J. Dairy Sci. 92:5031-5042.

Hurvich, C. M., and C.-L. Tsai. 1989. Regression and time series model selection in small samples. Biometrika 76:297-307.

Kammes, K., and M. Allen. 2012. Rates of particle size reduction and passage are faster for legume compared with cool-season grass, resulting in lower rumen fill and less effective fiber. J. Dairy Sci. 95:3288-3297.

Krizsan, S., A. Sairanen, A. Höjer, and P. Huhtanen. 2014. Evaluation of different feed intake models for dairy cows. J. Dairy Sci. 97:2387-2397.

Kuznetsova, A., P. Brockhoff, and R. Christensen. 2013. lmerTest: Tests for random and fixed effects for linear mixed effect models (lmer objects of lme4 package). $\mathrm{R}$ package version:2.0-0. Comprehensive R Archive Network. Accessed Mar. 15, 2015. http://cran. uib.no/web/packages/lmerTest/.

Lee, C., A. Hristov, K. Heyler, T. Cassidy, H. Lapierre, G. Varga, and C. Parys. 2012. Effects of metabolizable protein supply and amino acid supplementation on nitrogen utilization, milk production, and ammonia emissions from manure in dairy cows. J. Dairy Sci. 95:5253-5268.

Lin, L. I. 1989. A concordance correlation coefficient to evaluate reproducibility. Biometrics 45:255-268.

Lopes, F., D. Cook, and D. Combs. 2015. Validation of an in vitro model for predicting rumen and total-tract fiber digestibility in dairy cows fed corn silages with different in vitro neutral detergent fiber digestibilities at 2 levels of dry matter intake. J. Dairy Sci. 98:574-585.

Merchen, N., J. Elizalde, and J. Drackley. 1997. Current perspective on assessing site of digestion in ruminants. J. Anim. Sci. 75:22232234 .

Mould, F., E. Ørskov, and S. Mann. 1983. Associative effects of mixed feeds. I. Effects of type and level of supplementation and the influence of the rumen fluid $\mathrm{pH}$ on cellulolysis in vivo and dry matter digestion of various roughages. Anim. Feed Sci. Technol. 10:15-30.

Murphy, T., S. Loerch, and F. Smith. 1994. Effects of feeding highconcentrate diets at restricted intakes on digestibility and nitrogen metabolism in growing lambs. J. Anim. Sci. 72:1583-1590.

Ndegwa, P. M., A. N. Hristov, J. Arogo, and R. E. Sheffield. 2008. A review of ammonia emission mitigation techniques for concentrated animal feeding operations. Biosystems Eng. 100:453-469.

Nolan, J. 1975. Quantitative models of nitrogen metabolism in sheep. Pages 416-431 in Digestion and Metabolism in the Ruminant. Vol. 416. I. W. McDonald and A. C. I. Warner, ed. The University of New England Publishing Unit, Armidale, New South Wales, Australia.

NRC. 2001. Nutrient Requirements of Dairy Cattle. 7th ed. National Academy Press, Washington, DC.
Offner, A., A. Bach, and D. Sauvant. 2003. Quantitative review of in situ starch degradation in the rumen. Anim. Feed Sci. Technol. 106:81-93

Palmonari, A., A. Gallo, M. Fustini, G. Canestrari, F. Masoero, C. J. Sniffen, and A. Formigoni. 2016. Estimation of the indigestible fiber in different forage types. J. Anim. Sci. 94:248-254.

Philippeau, C., J. Landry, and B. Michalet-Doreau. 2000. Influence of the protein distribution of maize endosperm on ruminal starch degradability. J. Sci. Food Agric. 80:404-408.

R Core Team. 2014. R: A language and environment for statistical computing. R Foundation for Statistical Computing, Vienna, Austria. http://www.R-project.org/.

Ranathunga, S., M. Abdelqader, and K. Kalscheur. 2013. Nutrient digestion by dairy cows fed diets replacing starch with non-forage fiber. Pages 61-63 in Energy and protein metabolism and nutrition in sustainable animal production. Springer.

Reed, K., L. Moraes, D. Casper, and E. Kebreab. 2015. Predicting nitrogen excretion from cattle. J. Dairy Sci. 98:3025-3035.

Robert, C., and G. Casella. 2013. Monte Carlo Statistical Methods. Springer Science \& Business Media, Berlin, Germany.

Roman-Garcia, Y., R. R. White, and J. Firkins. 2016. Meta-analysis of postruminal microbial protein flows in dairy cattle. I. Derivation of equations. J. Dairy Sci. 99:7918-7931. http://dx.doi.org/10.3168/ jds.2015-10661.

Russell, J., J. O'connor, D. Fox, P. Van Soest, and C. Sniffen. 1992. A net carbohydrate and protein system for evaluating cattle diets: I. Ruminal fermentation. J. Anim. Sci. 70:3551-3561.

Stevens, C., R. Argenzio, and E. Clemens. 1980. Microbial digestion: Rumen versus large intestine. Pages 685-706 in Digestive Physiology and Metabolism in Ruminants. Y. Ruckebusch and P. Thivend, ed. AVI Publishing Co. Inc., Westport, CT.

Tedeschi, L. O., D. G. Fox, M. A. Fonseca, and L. F. L. Cavalcanti. 2015. Models of protein and amino acid requirements for cattle. Rev. Bras. Zootec. 44:109-132.

Van Amburgh, M., E. Collao-Saenz, R. Higgs, D. Ross, E. Recktenwald, E. Raffrenato, L. Chase, T. Overton, J. Mills, and A. Foskolos. 2015. The Cornell Net Carbohydrate and Protein System: Updates to the model and evaluation of version 6.5. J. Dairy Sci. 98:6361-6380

Vanhatalo, A., and E. Ketoja. 1995. The role of the large intestine in post-ruminal digestion of feeds as measured by the mobile-bag method in cattle. Br. J. Nutr. 73:491-505.

White, R. R., M. D. Hanigan, and L. O. Tedeschi. 2015. Comparing meta-regression, weighted least-square regression, and orthogonal regression for quantitative literature summary. Can. J. Anim. Sci 95:640-641.

Wylie, M., W. Ellis, J. Matis, E. Bailey, W. James, and D. Beever. 2000. The flow of forage particles and solutes through segments of the digestive tracts of cattle. Br. J. Nutr. 83:295-306.

Yang, W., K. Beauchemin, and L. Rode. 2002. Effects of particle size of alfalfa-based dairy cow diets on site and extent of digestion. J. Dairy Sci. 85:1958-1968.

Yu, P., D. Christensen, and J. McKinnon. 2003. Comparison of the National Research Council-2001 model with the Dutch system (DVE/OEB) in the prediction of nutrient supply to dairy cows from forages. J. Dairy Sci. 86:2178-2192. 